\title{
Activation of DI/5 Dopamine Receptors: A Common Mechanism for Enhancing Extinction of Fear and Reward-Seeking Behaviors
}

\author{
Antony D Abraham ${ }^{*, 1}$, Kim A Neve ${ }^{1,2}$ and K Matthew Lattal' \\ 'Department of Behavioral Neuroscience, Oregon Health \& Science University, Portland, OR, USA; ${ }^{2}$ Research Service, VA Portland Health Care \\ System, Portland, OR, USA
}

\begin{abstract}
Dopamine is critical for many processes that drive learning and memory, including motivation, prediction error, incentive salience, memory consolidation, and response output. Theories of dopamine's function in these processes have, for the most part, been developed from behavioral approaches that examine learning mechanisms in appetitive tasks. A parallel and growing literature indicates that dopamine signaling is involved in consolidation of memories into stable representations in aversive tasks such as fear conditioning. Relatively little is known about how dopamine may modulate memories that form during extinction, when organisms leam that the relation between previously associated events is severed. We investigated whether fear and reward extinction share common mechanisms that could be enhanced with dopamine DI/5 receptor activation. Pharmacological activation of dopamine DI/5 receptors (with SKF 8I297) enhanced extinction of both cued and contextual fear. These effects also occurred in the extinction of cocaine-induced conditioned place preference, suggesting that the observed effects on extinction were not specific to a particular type of procedure (aversive or appetitive). A cAMP/PKA biased DI agonist (SKF 83959) did not affect fear extinction, whereas a broadly efficacious DI agonist (SKF 83822) promoted fear extinction. Together, these findings show that dopamine DI/5 receptor activation is a target for the enhancement of fear or reward extinction.

Neuropsychopharmacology (20 I6) 4I, 2072-208I; doi: I 0.I038/npp.20I6.5; published online I0 February 2016
\end{abstract}

\section{INTRODUCTION}

Analysis of dopamine neuron firing during reward tasks has indicated that rather than simply encoding the hedonic value of an unconditioned stimulus (US), dopamine neurons participate in the encoding of the discrepancy between expected and obtained outcomes (prediction error; Schultz and Dickinson, 2000). Although the major proportion of research on dopamine signaling in learning has focused on appetitive USs, many of the theoretical approaches that have been applied to dopamine make no obvious distinction between mechanisms involving appetitive or aversive USs (Salamone, 1994). Indeed, an emerging literature suggests the involvement of dopaminergic signaling in learning about aversive USs (eg, Matsumoto and Hikosaka, 2009).

The role of dopamine in aversive learning has been investigated primarily in the acquisition and maintenance of fear or avoidance learning (Iordanova et al, 2006; Rossato et al, 2009; Fadok et al, 2009; Zweifel et al, 2011; Pezze and Feldon, 2004). These studies have shown a requirement for dopamine signaling in some elements of aversive learning

* Correspondence: Dr A Abraham, Department of Behavioral Neuroscience, Oregon Health \& Science University, Portland, OR 97239, USA, Tel: +I 503418 2215, Fax: + I 5034946877 ,

E-mail: abrahama@uw.edu

Received 30 October 2015; revised 2I December 2015; accepted 7 January 2016; accepted article preview online 14 January 2016
(Inoue et al, 2000), but evidence suggesting that dopamine directly encodes prediction error in aversive learning has been primarily correlative (Iordanova, 2009).

One domain in which fear and reward prediction signals may overlap is in extinction, as conditioned stimuli (CSs) become weak predictors of aversive or rewarding USs. Dopamine is particularly responsive to conditioned stimuli (Schultz et al, 1993), suggesting that dopamine may encode an element of learning that is favored during extinction. What this element of learning is remains to be determined and there are various theoretical accounts of dopamine's function during extinction (Redgrave et al, 1999; Horvitz, 2000; Salamone, 1994).

Key to dissociating many of these accounts is the nature of the dopamine receptor and the signaling pathways that are activated by dopamine. Increases in the availability of dopamine in the synaptic cleft result in increased receptor binding and activation of multiple intracellular signaling cascades. Drugs such as methylphenidate, methamphetamine, and L-dopa appear to promote memory and extinction through this mechanism (Abraham et al, 2012; Wood and Anagnostaras, 2009; Carmack et al, 2010; Haaker et al, 2013), raising the potential for dopaminergic compounds in treating post-traumatic stress disorder (Raczka et al, 2011; Bukalo et al, 2014). Increased availability of dopamine causes activation of D1-like and D2-like dopamine receptors, but the memory-enhancing effects of dopamine receptor 
activation are hypothesized to be mediated by D1/5 receptors, as antagonizing D1/5 receptors blocks methylphenidate's actions on working memory (Arnsten and Dudley, 2005), and impairs consolidation of fear or reward extinction (Hikind and Maroun, 2008; Fricks-Gleason et al, 2012).

Most of the pharmacological and behavioral evidence for a role of D1/5 receptors in aversive memory comes from studies with D1/5 receptor antagonists (Menezes et al, 2015; Holtzman-Assif et al, 2010). Fewer studies have examined whether activating D1/5 receptors could promote memory and extinction, although studies with the partial agonist SKF 38393 have demonstrated both enhancements (Fiorenza et al, 2012; Rey et al, 2014) and impairments of fear extinction retention (Borowski and Kokkinidis, 1998). The discrepancies in the literature examining the effect of dopamine agonism on fear extinction may be due to the multiple signaling cascades induced by different agonists at particular doses (Andersen and Jansen, 1990). The differing pharmacological properties of D1/5 receptor agonists may have an impact on extinction learning and previous characterizations using only SKF 38393, a commonly used D1/5 receptor partial agonist, may not fully capture the impact of $\mathrm{D} 1 / 5$ receptor activation on fear behaviors.

The contribution of particular intracellular signaling pathways in fear extinction can be assessed through the use of D1 receptor agonists with differing biases for signaling pathways. For instance, although most D1 receptor agonists stimulate cyclic adenosine monophosphate (cAMP) accumulation in vitro, SKF 38393 and SKF 83959 do not strongly induce recruitment of arrestin or D1 receptor internalization, signaling mechanisms that are efficaciously activated by the full agonists SKF 81297 and SKF 83822 (Conroy et al, 2015). Thus, SKF 38393 and SKF 83959 are biased towards cAMP signaling. The effect of biased activation of D1 receptor signaling pathways on fear extinction remains untested.

The goal of the studies presented here is to specify the contribution of $\mathrm{D} 1 / 5$ receptor activation to fear and reward extinction. To examine the content of learning produced by SKF 81297, we tested the rewarding properties of SKF 81297 with conditioned place preference (CPP) and the impact of SKF 81297 on cocaine CPP extinction. Finally, the intracellular signaling requirements for enhanced fear extinction were assessed through the use of biased (SKF 83959) or unbiased (SKF 83822) D1/5 receptor agonists.

\section{MATERIALS AND METHODS}

\section{Subjects}

Male C57BL/6J mice $(n=314)$ ranging from 7 to 11 weeks of age $(28 \pm 5 \mathrm{~g})$ were used in these experiments (Jackson Laboratories). Animals were housed four to a cage, and given food and water ad libitum. All experimental procedures were approved by the OHSU Institutional Animal Use and Care Committee and were conducted in accordance with National Institutes of Health, 1985 (NIH) 'Principles of Laboratory Animal Care' (NIH Publication No. 86-23, revised 1985).

\section{Drugs}

SKF 81297 (Tocris Bioscience, Bristol, UK) was dissolved in saline $(0.9 \% \mathrm{NaCl})$ at concentrations of 1,3 , and $10 \mathrm{mg} / \mathrm{kg}$.
Gentle heating was used to dissolve SKF 81297 at $10 \mathrm{mg} / \mathrm{kg}$ in saline. Cocaine $(20 \mathrm{mg} / \mathrm{kg})$ was dissolved in saline. Both drugs were administered intraperitoneally (i.p.) in a volume of $10 \mathrm{ml} / \mathrm{kg}$. SKF 83822 and SKF 83959 (Tocris) were dissolved in $10 \%$ DMSO (dimethyl sulfoxide in distilled water) and administered subcutaneously. Drug dosing for SKF $83822(0.1,1,2 \mathrm{mg} / \mathrm{kg})$ and SKF $83959(0.1,1,10 \mathrm{mg} / \mathrm{kg})$ were estimated based on doses used by O'Sullivan et al (2008).

\section{Apparatus}

Fear conditioning. Four Coulbourn Instruments (Whitehall, PA) mouse-conditioning floors housed in sound-attenuating cabinets were used with a Plexiglass cylinder $(21.5 \mathrm{~cm}$ in diameter and $23 \mathrm{~cm}$ in height) placed on the chamber floor. Scrambled shock $(2 \mathrm{~s}, 0.35 \mathrm{~mA})$ was delivered to the grid floor by a computer controlled shock generator (Coulbourn H13-15). For cued conditioning, an $85 \mathrm{~dB}$ white noise $\mathrm{CS}$ was administered through a sound generator (Coulbourn A12-33). Above the Plexiglas cylinder, an automated infrared activity monitor (Coulbourn H24-61) recorded activity in Graphic State 3.01 software. Contextual fear conditioning studies were conducted in these chambers, and fear conditioning and context testing occurred in these chambers for cued fear studies (Context A). Testing for cued conditioning was conducted in a separate room in rectangular conditioning chambers (Context B; Med-Associates, St Albans, VT). Data in Context B were hand scored for analysis. Contexts were cleaned with $95 \%$ ethanol following each session.

Conditioned place preference. Eight sound- and light-attenuating cabinets contained clear acrylic cages $(30 \mathrm{~cm} \times 15 \mathrm{~cm} \times 15 \mathrm{~cm})$ with two distinct removable floor types (grid or hole) as interchangeable halves. Position in the box (left/right side) and general activity were assessed by EthoVision XT 5 software (Noldus, Leesburg, VA) that recorded and analyzed the position of the center point of the mouse within the apparatus via a ceiling mounted camera.

Locomotor activity. Eight sound and light-attenuating cabinets contained a Plexiglas cylinder (identical to the size of the fear conditioning chambers) placed on the floor of the chamber. Total activity in the box was assessed by Ethovision 5.0.216 software (Noldus, Leesburg, VA) that recorded activity via a ceiling mounted camera.

\section{Behavioral Procedures}

Contextual fear extinction. Animals were handled and injected with saline for 2 days prior to all experiments. On Day 1, subjects received a 12-min exposure to the context with four unsignaled shocks, delivered at 2.5, 5, 9, and $11.5 \mathrm{~min}$. In pre-extinction injection experiments, groups were matched following conditioning to ensure equal terminal freezing levels across drug dose assignments. On Day 2, mice received an injection of vehicle or drug immediately prior to ( $n=8$ per group) or following ( $n=10-12$ per group) an extinction session (12-min nonreinforced exposure to the context). Mice receiving post-session drug were returned to their home cage immediately following drug or vehicle administration. 
In all post-extinction injection experiments, groups were matched following extinction to ensure equal levels of terminal freezing before drug administration. Control groups receiving no extinction remained in the vivarium, where they received a saline $(n=10)$ or SKF $81297(10 \mathrm{mg} / \mathrm{kg} ; n=10)$ injection. On Test Day, mice received a 12 -min nonreinforced exposure to the context. In the extinction $v s$ no extinction experiment (Figure 1e), one chamber was removed from analysis due to an equipment malfunction during fear conditioning, leading to the removal of four animals from the experiment (2 SKF/Ext, $1 \mathrm{SKF} /$ No Ext, 1 Sal/No Ext). The reported sample sizes reflect the analysis following removal of the malfunctioning box.

Locomotor effects of pre- or post-session SKF 81297. Locomotor testing followed an identical protocol to the fear extinction experiment described above (same cylindrical chambers, same session durations), except that no shock was delivered on Day 1. Activity was assessed over 3 days, with animals ( $n=8$ per group) receiving a saline injection prior to or following placement into the locomotor chamber on Day 1 for $12 \mathrm{~min}$. Animals were matched for locomotor activity on Day 1 then received SKF $81297(10 \mathrm{mg} / \mathrm{kg})$ or saline immediately prior to or following placement into the locomotor chamber on Day 2 for $12 \mathrm{~min}$. On Day 3, animals received an injection of saline prior to or following exposure to the locomotor chamber.

Post-extinction SKF 81297 effect on cued fear and renewal. On Day 1, subjects ( $n=8$ per group) received a $6.5-\mathrm{min}$ exposure to Context A with a 30 -s noise CS at 2 and $4 \mathrm{~min}$, co-terminating with shock presented at 2.5 and $4.5 \mathrm{~min}$. On Day 2, mice received a 6-min nonreinforced exposure to Context A. Groups were matched for freezing during Days 1 and 2. On Day 3, mice were placed in Context B for 15 min with 3 -min CS presentations at 3 and $9 \mathrm{~min}$. Immediately following the extinction session on Day 3, mice were administered SKF 81297 (10 mg/kg) or saline. On Days 4-7 (Tests 1-4), subjects were placed in Context B for 15-min with 3-min CS presentations at 3 and $9 \mathrm{~min}$. On Day 8, to measure fear renewal, mice were returned to Context $\mathrm{A}$ for a 15-min session with 3-min CS presentations at 3 and 9 min. Twenty-one days later, to measure retention of fear, mice were returned to Context A for a 15-min session with 3-min CS presentations at 3 and $9 \mathrm{~min}$. Freezing is shown for both CS-on and CS-off periods.

SKF 81297 generation of conditioned place preference. The rewarding properties of pre- or post-session SKF 81297 were tested using an unbiased CPP apparatus and procedure (Cunningham et al, 2006). Prior to conditioning, mice ( $n=16$ per group) were habituated (pretest) to the CPP apparatus by receiving a saline injection followed by a 5 -min exposure to the conditioning chamber with grid and hole floors. Animals were matched following pretest to ensure no bias to hole or grid floors, and then assigned to counterbalanced groups that received SKF $81297(10 \mathrm{mg} / \mathrm{kg})$ or saline immediately before or after exposure to a grid or hole floor. During conditioning, animals were confined to one half of the CPP apparatus with grid or hole floor for 15-min. Mice received one pairing of SKF 81297 (pre- or post-session) and one pairing of saline (pre- or post-session), counterbalanced for order and floor type, on alternating days. Twenty-four hours following the last conditioning session, mice were given a 15-min exposure to the CPP apparatus (Test Day) with both floors to assess preference for the drug-paired side.

Post-extinction SKF 81297 modulation of cocaineconditioned place preference. Animals ( $n=24$ per group) were matched following pretest to ensure no bias to hole or grid floors, and then assigned to counterbalanced groups that received cocaine $(20 \mathrm{mg} / \mathrm{kg})$ or saline immediately before exposure to a grid or hole floor. During conditioning, animals were confined to one half of the CPP apparatus with grid or hole floor for 15-min. Mice received two pairings of cocaine and two pairings of saline, counterbalanced for order and floor type, on alternating days. To minimize the possibility of a side preference, floor placement was alternated such that animals received a pairing of cocaine or saline on both right and left sides of the chamber (Hitchcock et al, 2014). Twentyfour hours following the last conditioning session, mice were given a 5-min exposure to the CPP apparatus with both floors to assess preference for the drug-paired side (Pre-Ext Test). A 5-min, rather than 15-min, test session was used to reduce within-session extinction. Seventy-two hours later, mice were placed in the conditioning apparatus for 15-min and confined to the drug-paired side for an extinction session. Immediately following extinction, animals received SKF $81297(10 \mathrm{mg} / \mathrm{kg})$ or saline. $24 \mathrm{~h}$ following extinction, mice received a 15 -min exposure to the conditioning apparatus with both floors to assess preference for cocaine-paired side (Post-Ext Test). Mice received three extinction sessions, then a cocaine-primed $(5 \mathrm{mg} / \mathrm{kg})$ reinstatement test followed by one additional extinction session.

\section{Data Analysis}

Freezing was defined as an episode of $>3$ s of inactivity. For contextual fear, total freezing time was divided by the session duration to calculate percentage of time freezing; for cued fear, freezing during the CS was divided by the CS duration. For the cued fear experiment, all data were hand-scored (using a time sampling technique of assessing freezing every $8 \mathrm{~s}$ ) due to the lack of an automated measurement system in Context B. Locomotor activity was measured in Ethovision by total distance moved in $\mathrm{cm}$, and reported as distance moved $(\mathrm{cm})$ per min. CPP was measured in Ethovision by time (s) spent on drug-paired floor (CS+) or vehicle-paired floor $(\mathrm{CS}-)$ per min of test session, which was used to calculate percentage of time spent on CS+ floor. Data analyses were performed with Prism 6. Data were analyzed using a Student's $t$-test, or one-way or two-way between subjects analysis of variance (ANOVA) on each day. All post hoc comparisons were performed using a Dunnett's test or Holm-Sidak test. For all statistical tests, the $\alpha$ was set to 0.05 .

\section{RESULTS}

\section{Dopamine D1/5 Receptor Agonism with SKF 81297 Enhances Fear Extinction}

Pre-extinction SKF 81297 caused a dose-dependent reduction in freezing during the extinction session (Ext in 

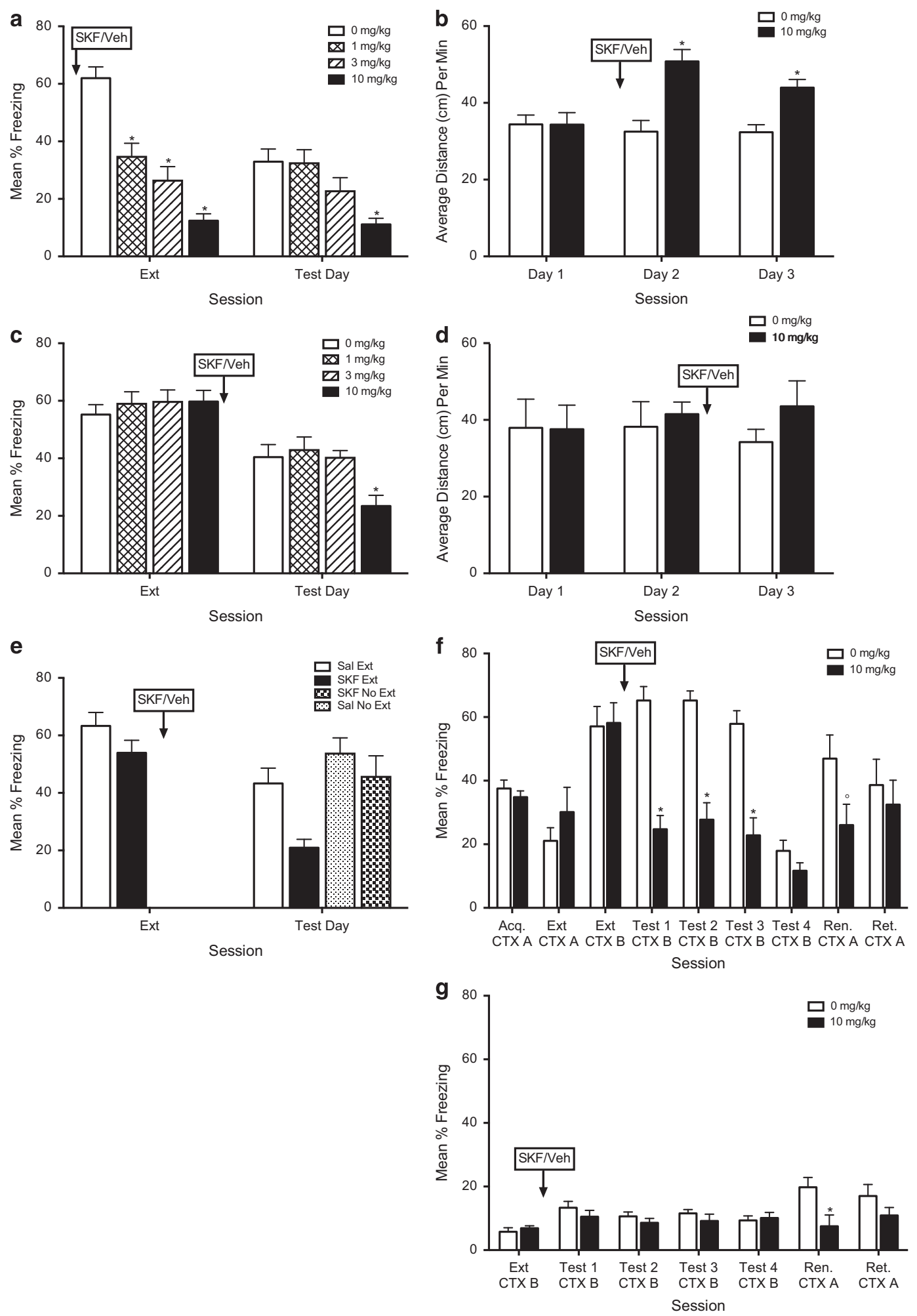

Figure I DI/5 receptor agonist SKF 81297 enhances fear extinction. (a) Mice that received pre-extinction SKF 8I297 showed differences in freezing response during Extinction (I, 3, and $10 \mathrm{mg} / \mathrm{kg}$ ) and Test Day $(10 \mathrm{mg} / \mathrm{kg})$. (b) Mice that received pre-session SKF 81297 (I0 mg/kg) showed increased locomotor behavior on Day 2 and Day 3. (c) Mice that received SKF 81297 (10 mg/kg) immediately following extinction showed significantly less freezing than saline-treated animals during Test Day I. (d) Mice that received post-session SKF 81297 ( I $0 \mathrm{mg} / \mathrm{kg}$ ) on Day 2 did not show a persistent increase of locomotor activity on Day 3. (e) SKF 81297 treatment in combination with extinction decreases freezing compared with animals receiving saline with or without extinction and SKF 8/297 without extinction, although there was not a significant interaction between SKF 8I297 treatment and extinction. (f and g). Post-session SKF 8/297 (10 mg/kg) enhances extinction of cued fear and impairs fear renewal. (f) Freezing during CS-on periods and (g) Freezing during CS-off periods. Mice that received post-session SKF $81297(10 \mathrm{mg} / \mathrm{kg}$ ) following cued extinction session showed decreased freezing during cue presentations (a) on Test I-3, and trended toward significant differences during cue presentations in renewal. Error bars indicate SEM. * $p<0.05$ significant difference compared with saline. ${ }^{\circ} \mathrm{p}=0.0535$. 
Figure 1a; F $(3,28)=26.153, p<0.0005)$. Saline was significantly different from $1 \mathrm{mg} / \mathrm{kg} \quad(p<0.0005), \quad 3 \mathrm{mg} / \mathrm{kg}$ $(p<0.0005)$, and $10 \mathrm{mg} / \mathrm{kg}(p<0.0005)$. During Test Day (Figure 1a), SKF 81297-treated mice showed less freezing than saline-treated mice $(\mathrm{F}(3,28)=6.094, p=0.003)$. Saline was significantly different from $10 \mathrm{mg} / \mathrm{kg}$ SKF 81297 $(p=0.003)$, but not $1 \mathrm{mg} / \mathrm{kg}$ or $3 \mathrm{mg} / \mathrm{kg}$. A separate experiment found that pre-session injections of $10 \mathrm{mg} / \mathrm{kg}$ SKF 81297 caused increases in locomotor activity (Figure 1b) following the injection on Day $2,(t(14)=4.304, p=0.0007)$ and during a drug-free test on Day $3(t(14)=4.031$, $p=0.0012$ ).

To overcome these acute locomotor effects, we administered SKF 81297 after extinction (Figure 1c) or after a locomotion session (Figure 1d). Post-extinction administration of SKF $81297(10 \mathrm{mg} / \mathrm{kg})$ caused a reduction in freezing $24 \mathrm{~h}$ later during the test session (Test Day in Figure 1c; $(\mathrm{F}(3,44)=5.328, p=0.0005)$. Saline was significantly different from $10 \mathrm{mg} / \mathrm{kg}$ SKF $81297 \quad(p=0.009)$. A separate experiment confirmed that post-session SKF 81297 did not significantly alter locomotor activity (Figure 1d; Day 3) compared to saline $(t(14)=1.256, p=0.230)$.

Figure 1e shows the effect of SKF 81297 administration on long-term freezing behaviors after the compound was delivered either in the presence or absence of extinction. Animals in extinction groups received $10 \mathrm{mg} / \mathrm{kg}$ SKF 81297 (SKF/Ext; $n=10)$ or saline immediately after extinction (Sal/Ext; $n=12$ ); animals in the no-extinction groups received $10 \mathrm{mg} / \mathrm{kg}$ SKF 81297 (SKF/No Ext; $n=11$ ) or saline in the vivarium (Sal/No Ext; $n=10$ ). Figure 1e shows that there were no significant differences during extinction, but the SKF 81297 Ext group showed reduced freezing at test (Test Day in Figure 1e). A two-way ANOVA revealed main effects of extinction $(\mathrm{F}(1,39)=9.724, p=0.003)$ and drug administration $(\mathrm{F}(1,39)=7.376, p=0.0098)$ during the test. There was no extinction $\mathrm{x}$ drug interaction $(\mathrm{F}(1,39)=1.620$, $p=0.211$ ), but post hoc analyses found that SKF/Ext was significantly different from Sal/Ext $(p=0.019)$, SKF/No Ext $(p=0.011)$, and Sal/No Ext $(p=0.008)$.

To assess the context specificity of the effect of SKF 81297 on extinction, cued fear extinction occurred in a novel context (Context B) with SKF 81297 administration, then renewal and long-term retention of fear was measured in the context of conditioning (Context A; Figure if and g). There were no differences in fear conditioning or contextual extinction in Context A (Ext CTX A in Figure 1f), and animals were matched for freezing during the first extinction session in Context B. Immediately following the extinction session, mice received either SKF 81297 (10 mg/kg) or saline, then were tested for several days until reaching equivalent levels of freezing. There were no significant differences between groups during Test Days on freezing during CS-off periods (Figure 1g), but differences emerged during presentations of the auditory CS (Figure 1f). On Test Days 1-3 in Figure 1f, SKF 81297 treated animals showed significantly less freezing than saline-treated animals $(t$ (14) >5.1, $p<0.0005)$. By Test Day 4 , both groups had extinguished to equivalent levels $(t(14)=1.509, p=0.1536)$.

The following day, animals were returned to the conditioning context (Context A) to measure fear renewal. There was a trend towards decreased freezing during the CS-on period $(t(14)=2.108, p=0.0535$; Ren. in Figure 1f) and a significant decrease in freezing during CS-off period $(t(14)=2.598, p=0.0211$; Figure 1g) in SKF-treated mice. There were no differences between groups during the 21-day retention test (Ret. in Figure 1f and g). This experiment suggests that the SKF 81297 promoted extinction of cued fear and that enhanced extinction effects generalize back to the conditioning context.

\section{Post-session SKF 81297 Does not Generate CPP and Enhances Extinction of Cocaine CPP}

We tested the rewarding properties of SKF 81297 by using it as a US in a CPP procedure. Previous experiments have found that the rewarding properties of a drug may differ depending on when it is delivered relative to context exposure-pre-session injections lead to CPP; post-session injections lead to conditioned place aversion (CPA; Cunningham et al, 1998). Pre-session injections of SKF 81297 (SKF Pre-Tx) during acquisition generated CPP that was reliably different from post-session SKF 81297 $(t(30)=2.962, p=0.006$; Figure 2a; SKF Post-Tx). Compared with a $50 \%$ (no preference) baseline value, pre-session SKF 81297 induced a preference $(t(15)=10.28, p<0.0001)$ but post-session SKF 81297 did not $(t(15)=1.040, p=0.315)$. This suggests that SKF 81297 has rewarding properties when administered prior to a session, but we detected neither rewarding nor aversive properties when administered after a session.

We next asked whether the extinction enhancing effects that we observed in fear extinction would also occur in extinction of cocaine-induced CPP. If the rewarding value of SKF81297 becomes associated with the context in which it is delivered, then delivery of the drug during extinction of a cocaine-induced preference may prevent the loss of CPP. Figure $2 \mathrm{~b}$ shows that groups did not differ in preference before extinction, but there was a non-significant trend toward decreased preference in animals that received SKF 81297 compared to saline $(t(46)=1.730, p=0.090)$ during the post-extinction test (Post-Ext Test in Figure $2 \mathrm{~b}$ ).

The trend for decreased preference in SKF 81297-treated mice during the Post-Extinction test led us to examine whether initial preference influenced the effect of SKF 81297 on extinction (Weber et al, 2007; Bernardi and Lattal, 2012; Gruene et al, 2015). To assess high or low cocaine preference, a median preference value was calculated from all subjects (48 animals) during the Pre-Ext Test, which occurred prior to delivery of SKF 81297. Animals that fell below the median of $65 \%$ preference were characterized as low-preference (Figure 2c); animals above 65\% were high-preference (Figure 2d). For the saline-treated group, 10 mice were low-preference, and 14 were high-preference. For the SKF-treated group, 14 mice were low-preference, and 10 were high-preference.

There were no effects of SKF 81297 on extinction in low preference animals $(\mathrm{F}(1,22)=1.9, p=0.19$; Figure $2 \mathrm{c})$. Groups showed little extinction, revealed as a change from the Pre-Ext test to the Post-Ext test (no reliable main effect of session or session $x$ drug interaction: $\mathrm{F}(1,22)<1.0)$. However, an effect of SKF 81297 was evident in mice that showed high preference during the Pre-Ext test (Figure 2d). A Drug (SKF 81297 vs saline) $\times$ Session (Pre- vs Post-Ext) ANOVA revealed a reliable main effect of Session 
a $\quad$ Rewarding Properties of SKF 81297

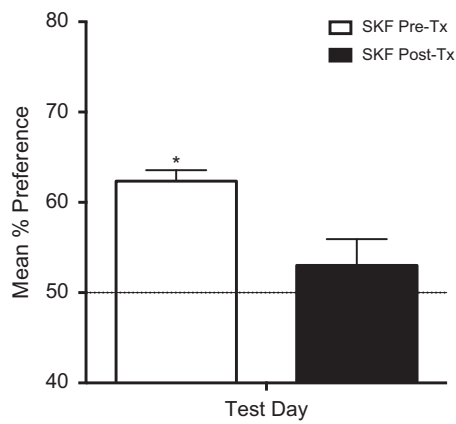

C

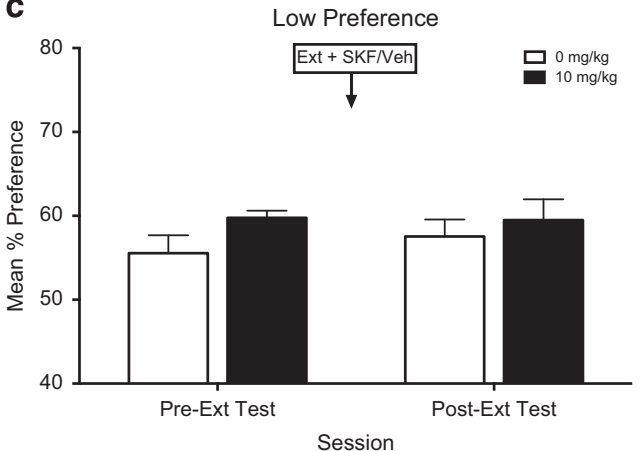

b

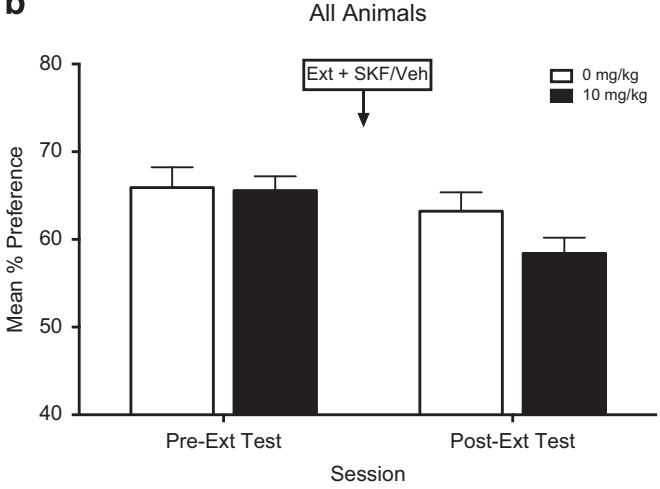

d

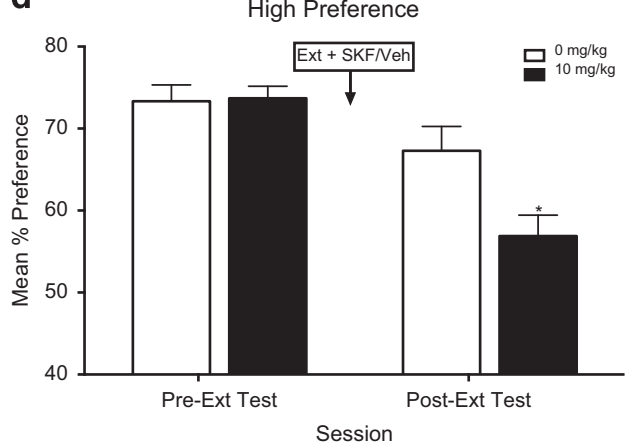

Figure 2 Pre-session SKF 81297 induces CPP and post-session SKF 81297 promotes cocaine CPP extinction. (a) Mice that received pre-session administration of SKF 81297 (SKF Pre-Tx) showed significantly more preference for drug-paired side than post-session treated animals (SKF Post-Tx). (b) Mice that received post-extinction administration of SKF 81297 trended towards decreased preference for cocaine-paired side. (c) Mice with low preference showed no difference between groups. (d) Mice with high preference (over 65\%) showed significantly decreased preference for cocaine-paired side with postextinction SKF 81297 compared with saline-treated mice. Error bars indicate SEM. * $p<0.05$ significant difference compared with saline.

$(\mathrm{F}(1,22)=29.6, p<0.0001)$ and Session $\times$ Drug interaction $(\mathrm{F}(1,22)=6.6, p<0.02)$. Post hoc analysis of the interaction revealed that although there was no significant difference between the Pre-Ext Test and Post-Ext Test in saline-treated mice $(p=0.0715)$, SKF 81297-treated animals showed significantly less preference for the drug-paired floor during the Post-Ext Test compared with Pre-Ext Test $(p<0.0001)$. There were no differences between groups in subsequent repeated extinction or reinstatement sessions (data not shown) and there were no differences in locomotion between SKF 81297- and saline-treated groups (Supplementary Figure 1). This experiment suggests that SKF 81297 promoted extinction of a cocaine-induced CPP in animals that express a high preference prior to extinction.

\section{cAMP/ $\beta$-Arrestin Biased and Unbiased D1/5 Receptor Agonists have Dissociable Effects on Fear Extinction}

To determine the intracellular signaling requirements for D1/5 receptor-mediated extinction enhancements, we examined the effects of a D1 receptor cAMP biased agonist (SKF 83959) or the cAMP/ $\beta$-arrestin unbiased D1 receptor agonist (SKF 83822) on fear extinction (Figure 3). SKF 83959-treated and vehicle-treated mice did not differ during the test $(\mathrm{F}(3,28)=0.8069, p=0.5007)$, indicating that activation of $\mathrm{D} 1 / 5$ receptor-coupled cAMP pathways may not be sufficient to enhance extinction (Figure 3a). SKF 83822, however, significantly decreased fear responding compared with vehicle $(\mathrm{F}(3,28)=4.857, p=0.0076 ; 1 \mathrm{mg} / \mathrm{kg}$
SKF 83822 vs vehicle, $p=0.0397)$, suggesting an extinction enhancement by $c A M P / \beta$-arrestin unbiased activation of D1/5 receptors.

\section{DISCUSSION}

The experiments presented here demonstrate that fear extinction was enhanced by the D1/5 agonist SKF 81297. The dose of the drug that caused extinction enhancements also was rewarding, as shown with a CPP procedure in which SKF 81297 was administered before placement into a distinct context. This suggests that some of the extinction enhancements could be due to counterconditioning of the fearful context by a US with positive valence. The rewarding value of the drug, however, does not account for all of our effects because post-session injections of SKF 81297, which promoted fear extinction, did not induce CPP. Further, when administered after extinction of cocaine-induced CPP, the drug also promoted extinction in subjects expressing a high preference prior to extinction. Together, these findings suggest that D1/5 receptor signaling mediates extinction in aversive and reward learning paradigms.

Any interpretation of the behavioral effects of a drug that alters dopamine function must consider the potential effects of that drug on locomotion. As dopamine released from the substantia nigra is critical for motor behaviors and striatally driven behaviors (Andersson et al, 2006), it may be difficult to completely dissociate motoric components of dopamine 


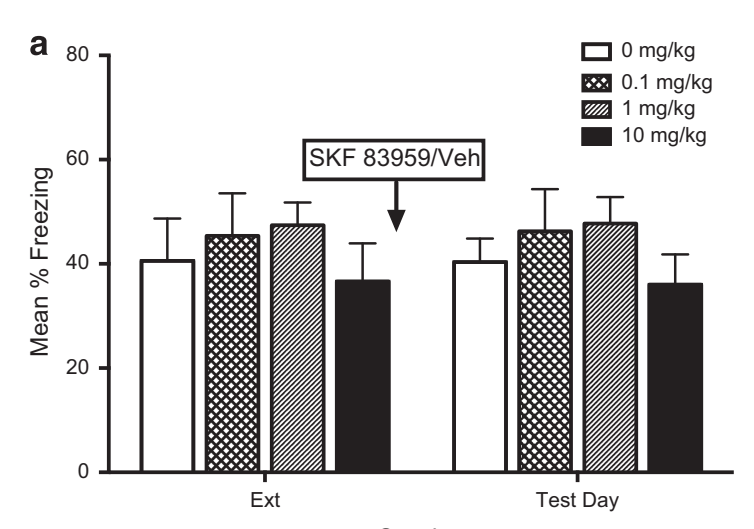

Session

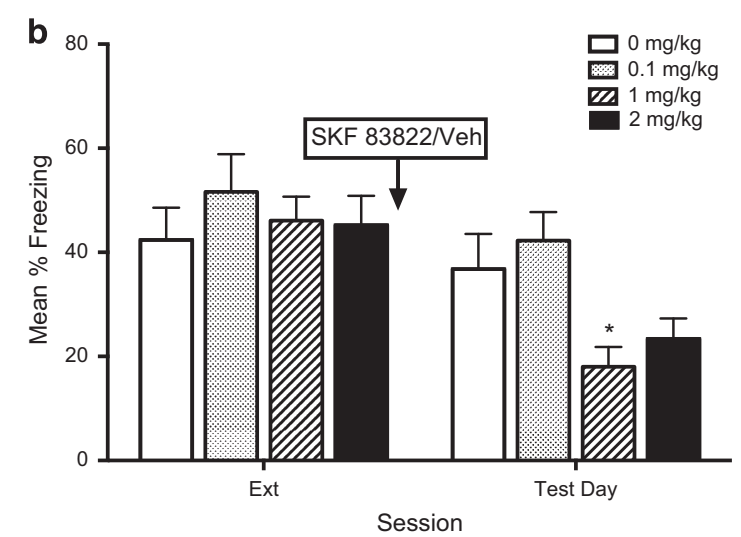

Figure 3 The biased DI agonist SKF 83959 does not affect fear extinction, but the broadly efficacious DI agonist SKF 83822 enhances fear extinction. (a) Mice that received SKF 83959 immediately following extinction showed no difference in freezing compared to vehicle-treated mice during Test Day. (b) Mice that received SKF 83822 $(\mathrm{l} \mathrm{mg} / \mathrm{kg})$ immediately following extinction showed a significant difference in freezing compared to vehicle-treated mice during Test Day. Error bars indicate SEM. *p $<0.05$ significant difference compared with vehicle.

neurotransmission and D1/5 receptor activation from expression of the motor behaviors associated with aversive and reward learning (Chausmer and Katz, 2002; Diaz Heijtz and Castellanos, 2006). It is possible that even a subtle effect of D1/5 activation on locomotion could influence the effects on behavior. In the case of fear extinction and CPP extinction, any increase in activity would impact the expression of freezing or CPP (Gremel and Cunningham, 2007; Groblewski et al, 2009; Lattal and Maughan, 2012), which could be interpreted as an enhancement in extinction when it actually is an artifact of persistent locomotor effects. This is especially true in fear extinction, because activity is so suppressed that even a small effect on locomotion may reveal itself as an effect on freezing.

We addressed the locomotor issue in several ways. First, the use of post-session administration of SKF 81297 allows for some separation between motor and memory effects of agonist administration. We found no persistent effect of post-session SKF 81297 administration on locomotor activity or on freezing during CS-off periods in a novel extinction context, providing another indication that increased locomotor behavior is not sufficient for explaining the observed extinction enhancement effects. Second, we found that the fear extinction enhancement depended on the contiguous presentation of the fearful context with SKF-81297; injection of the drug in the absence of extinction had no effect on freezing. Third, we found no persistent effect of post-session SKF 81297 on locomotion in the CPP extinction experiment, demonstrating that differences in extinction of a preference emerged despite identical locomotor effects. Together, these findings suggest that nonspecific locomotor effects of SKF81297 alone cannot account for the extinction enhancements we observed here.

A consistent finding in our experiments was that SKF81297 promoted extinction of fear. This was true of extinction following unsignaled contextual conditioning as well as extinction of a cue following cued conditioning. This effect was persistent across time and contexts, was dependent on the temporal pairing of extinction with the compound, and occurred whether D1/5 activation occurred before or after extinction. Our finding of accelerated extinction and somewhat weakened contextual renewal is consistent with a finding from humans with L-dopa administration (Haaker et al, 2013), suggesting potential therapeutic efficacy in targeting dopaminergic systems in extinction (see also Raczka et al, 2011; Dubrovina and Zinov'eva, 2010). Although our experiments primarily focus on fear and reward extinction, Guarraci et al (1999) and others (Pezze and Feldon, 2004) have demonstrated that fear conditioning is also modulated by $\mathrm{D} 1 / 5$ receptor activation within specific brain regions. However, D1/5 receptor activation does not consistently enhance all types of aversive learning, as shown by Wietzikoski et al (2012) with systemic SKF 81297 in a conditioned avoidance task. Thus, D1/5 receptor activation may have a brain region-specific and task-specific role in fear, but may not generally promote all aversive learning.

The post-session effects suggest that some memory process that operates after extinction may be promoted. There are many possibilities for this, including consolidation of the prediction error that occurred in extinction (Abraham et al, 2014), a D1-mediated prolonged window of inhibitory memory activity (Wagner, 1981), or counterconditioning of aversive fear memory by the rewarding properties of SKF81297 (Holmes and Westbrook, 2014). Our findings that SKF81297 induced a CPP when it was used as the US suggest that counterconditioning is a possibility for the enhanced fear extinction effects, and previous studies have shown that fear learning is subject to opponent interactions between appetitive and aversive processes (Nasser and McNally, 2012). However, SKF81297 was ineffective as a US when administered after a session, which may mean that the post-fear extinction enhancement occurred through some other mechanism.

These post-session injections might not have resulted in an excitatory association between the context and the rewarding properties of the drug. This does not necessarily mean that rewarding properties did not contribute to the enhanced extinction effects because, for example, it is possible that the rewarding properties of the drug are different based on the expectation of an aversive outcome at the beginning of a fear extinction session (Dickinson and Balleine, 2002). The rewarding properties of pre-session SKF 81297, but not post-session SKF 81297, suggests that there may be multiple mechanisms by which SKF 81297 enhances extinction. Nonetheless, the post-session CPP findings, along with previous findings that $\mathrm{D} 1 / 5$ receptor activation can enhance 
fear acquisition (Guarraci et al, 1999), make it seem less likely that the rewarding properties of the drug alone accounted for the extinction enhancements.

If SKF 81297 were driving the enhancements in fear extinction by augmenting a reward prediction error, then one might expect that it should not promote extinction in preparations using an appetitive US, such as cocaine-induced $\mathrm{CPP}$. By this reasoning, the prediction error between the expected US (cocaine) and the obtained US (SKF 81297) should be small because both are rewarding USs. On the other hand, if SKF 81297 promotes extinction by more general mechanisms, one might expect it to enhance extinction regardless of the US that was used to establish conditioning. We found that a single injection of SKF 81297 promoted extinction of CPP in animals that expressed a high level of preference. That it did not affect low preference animals suggests that extinction enhancements are difficult to reveal at the low end of the performance scale. Based on these experiments, a common CS-prediction mechanism may underlie the extinction of both rewarding and aversive associations that is guided by $\mathrm{D} 1 / 5$ receptor activation. As there are multiple mechanisms through which $\mathrm{D} 1 / 5$ receptor activation may modify behavior, these behavioral effects may be dissociable by examining the molecular pathways underlying extinction enhancements.

The contrasting behavioral effects of SKF 83822 and SKF 83959 may be informative for $\mathrm{G}$ protein-coupled intracellular signaling pathways and networks of dopamine terminal regions involved in fear extinction enhancement. Recent in vitro evidence from Conroy et al (2015) showed that the biased signaling properties of SKF 83822 and 83959 may be derived from the effects of these agonists on D1-receptorcoupled cAMP and $\beta$-arrestin pathways. D1/5 receptor agonists that promoted extinction, such as SKF 81297 and SKF 83822, strongly induced cAMP accumulation, $\beta$-arrestin recruitment, and D1 receptor internalization in Conroy et al (2015). However, SKF 83959, a D1/5 receptor agonist that is biased toward cAMP accumulation (SKF 83959) with little effect on $\beta$-arrestin or receptor internalization, had no effect on fear extinction. As SKF 83959 and SKF 38393 share similar profiles for D1 receptor mediated cAMP accumulation and $\beta$-arrestin recruitment, previous studies showing impaired fear extinction with SKF 38393 (Borowski and Kokkinidis, 1998) may be due to the biased signaling properties of this agonist. However, unlike SKF 83959, SKF 38393 induces a modest level of D1 receptor internalization and D5 receptor mediated cAMP accumulation, suggesting that extinction enhancements previously observed with SKF 38393 (Fiorenza et al, 2012; Rey et al, 2014) may be from the overlapping pharmacological properties of SKF 81297, SKF 83822, and SKF 38393.

An alternative interpretation of the lack of effect of SKF 83959 on extinction is based on work identifying SKF 83822 as a protein kinase $\mathrm{A}$ (PKA)-coupled D1/5 receptor agonist and SKF 83959 as a phospholipase C (PLC)-coupled D1/5 receptor agonist (O'Sullivan et al, 2008; Beaulieu et al, 2015). According to this interpretation, activating PKA-coupled, but not PLC-coupled D1/5 receptors can enhance fear extinction. The distinct patterns of PKA vs PLC coupled $\mathrm{D} 1 / 5$ receptor expression (Nishi et al, 2011) might indicate that SKF 83822 (PKA-coupled D1/5R agonist) may specifically engage the cortical networks involved in fear extinction through activation of PKA-coupled D1/5 receptors, whereas SKF 83959 may primarily activate the amygdala and hippocampus without affecting fear extinction. Our studies are also in concordance with Menezes et al (2015), who demonstrated that novelty-induced enhancement of fear extinction is mediated via D1/5 receptor activation and PKA signaling.

Together, our findings show that D1/5 receptor agonists can promote extinction in preparations using appetitive or aversive outcomes. Although these compounds may have rewarding properties of their own, they promote extinction even in situations in which they should not be rewarding and they promote extinction of drug-seeking behaviors. These findings suggest that the effects of activating D1/5 receptors during extinction go beyond the specific hedonic properties of a given drug and instead may occur due to second messenger systems that are activated by $\mathrm{D} 1 / 5$ receptors. These systems likely require $\beta$-arrestin recruitment and/or D1 receptor internalization, in addition to cAMP accumulation/PKA activation, and may not require PLC-mediated signaling. Testing a broad range of D1/5 receptor agonists in fear extinction paradigms could specify a target pharmacological profile for the development of dopamine agonists (Neve, 2009) that would most effectively promote extinction (Maren and Holmes, 2016) with minimal side effects in patients seeking treatment for a range of disorders that involve aberrant dopamine signaling.

\section{FUNDING AND DISCLOSURE}

The authors declare no conflict of interest.

\section{ACKNOWLEDGMENTS}

This work was supported by NIH grants DA007262 (ADA), DA018165 (KML), DA025922 (KML), US Department of the Army/DOD-TATRC W81XWH-12-2-0048 (KML), and Merit Review Award BX000810 from the US Department of Veterans Affairs, Veterans Health Administration, Office of Research and Development, Biomedical Laboratory Research and Development (KAN).

\section{REFERENCES}

Abraham AD, Cunningham CL, Lattal KM (2012). Methylphenidate enhances extinction of contextual fear. Learn Mem 19: 67-72.

Abraham AD, Neve KA, Lattal KM (2014). Dopamine and extinction: a convergence of theory with fear and reward circuitry. Neurobiol Learn Mem 108: 65-77.

Andersen PH, Jansen JA (1990). Dopamine receptor agonists: selectivity and dopamine D1 receptor efficacy. Eur J Pharmacol 188: 335-347.

Andersson DR, Nissbrandt H, Bergquist F (2006). Partial depletion of dopamine in substantia nigra impairs motor performance without altering striatal dopamine neurotransmission. Eur $J$ Neurosci 24: 617-624.

Arnsten AF, Dudley A (2005). Methylphenidate improves prefrontal cortical cognitive function through $\alpha-2$ adrenoceptor and dopamine D1 receptor actions: relevance to therapeutic effects in Attention Deficit Hyperactivity Disorder. Behav Brain Funct 1: $2-11$. 
Beaulieu JM, Espinoza S, Gainetdinov RR (2015). Dopamine receptors-IUPHAR review 13. Br J Pharmacol 172: 1-23.

Bernardi RE, Lattal KM (2012). Prazosin differentially affects extinction of cocaine conditioned place preference on the basis of dose and initial preference. Neuroreport 23: 1048-1051.

Borowski TB, Kokkinidis L (1998). The effects of cocaine, amphetamine, and the dopamine D1 receptor agonist SKF 38393 on fear extinction as measured with potentiated startle: implications for psychomotor stimulant psychosis. Behav Neurosci 112: 952-965.

Bukalo O, Pinard CR, Holmes A (2014). Mechanisms to medicines: elucidating neural and molecular substrates of fear extinction to identify novel treatments for anxiety disorders. $\mathrm{Br} J$ Pharmacol 171: 4690-4718.

Carmack SA, Wood SC, Anagnostaras SG (2010). Amphetamine and extinction of cued fear. Neurosci Lett 468: 18-22.

Chausmer AL, Katz JL (2002). Comparison of interactions of D1-like agonists, SKF 81297, SKF 82958 and A-77636, with cocaine: locomotor activity and drug discrimination studies in rodents. Psychopharmacology (Berl) 159: 145-153.

Conroy JL, Free RB, Sibley DR (2015). Identification of G proteinbiased agonists that fail to recruit $\beta$-arrestin or promote internalization of the D1 dopamine receptor. ACS Chem Neurosci 6: 681-692.

Cunningham CL, Gremel CM, Groblewski PA (2006). Druginduced conditioned place preference and aversion in mice. Nat Protoc 1: 1662-1670.

Cunningham CL, Henderson CM, Bormann NM (1998). Extinction of ethanol-induced conditioned place preference and conditioned place aversion: effects of naloxone. Psychopharmacology (Berl) 139: $62-70$.

Diaz Heijtz R, Castellanos FX (2006). Differential effects of a selective dopamine D1-like receptor agonist on motor activity and c-fos expression in the frontal-striatal circuitry of SHR and Wistar-Kyoto rats. Behav Brain Funct 2: 18.

Dickinson A, Balleine B (2002). The role of learning in the operation of motivational systems. In: Gallistel CR (ed). Steven's Handbook of Experimental Psychology: Learning, Motivation and Emotion. 3rd edn, Vol. 3. John Wiley \& Sons: New York, pp 497-534.

Dubrovina NI, Zinov'eva DV (2010). Effects of activation and blockade of dopamine receptors on the extinction of a passive avoidance reaction in mice with a depressive-like state. Neurosci Behav Physiol 40: 55-59.

Fadok JP, Dickerson TM, Palmiter RD (2009). Dopamine is necessary for cue-dependent fear conditioning. J Neurosci 29: 11089-11097.

Fiorenza NG, Rosa J, Izquierdo I, Myskiw JC (2012). Modulation of the extinction of two different fear-motivated tasks in three distinct brain areas. Behav Brain Res 232: 210-216.

Fricks-Gleason AN, Khalaj AJ, Marshall JF (2012). Dopamine D1 receptor antagonism impairs extinction of cocaine-cue memories. Behav Brain Res 226: 357-360.

Gremel CM, Cunningham CL (2007). Role of test activity in ethanol-induced disruption of place preference expression in mice. Psychopharmacology (Berl) 191: 195-202.

Groblewski PA, Lattal KM, Cunningham CL (2009). Effects of D-cycloserine on extinction and reconditioning of ethanolseeking behavior in mice. Alcohol Clin Exp Res 33: 772-782.

Gruene TM, Roberts E, Thomas V, Ronzio A, Shansky RM (2015). Sex-specific neuroanatomical correlates of fear expression in prefrontal-amygdala circuits. Biol Psychiatry 78: 186-193.

Guarraci FA, Frohardt RJ, Kapp BS (1999). Amygdaloid D1 dopamine receptor involvement in Pavlovian fear conditioning. Brain Res 827: 28-40.

Haaker J, Gaburro S, Sah A, Gartmann N, Lonsdorf TB, Meier K et al (2013). Single dose of L-dopa makes extinction memories context-independent and prevents the return of fear. Proc Natl Acad Sci USA 110: 2428-2436.
Hikind N, Maroun M (2008). Microinfusion of the D1 receptor antagonist, SCH23390 into the IL but not the BLA impairs consolidation of extinction of auditory fear conditioning. Neurobiol Learn Mem 90: 217-222.

Hitchcock LN, Cunningham CL, Lattal KM (2014). Cue configuration effects in acquisition and extinction of a cocaine-induced place preference. Behav Neurosci 128: 217-227.

Holmes NM, Westbrook RF (2014). Appetitive context conditioning proactively, but transiently, interferes with expression of counterconditioned context fear. Learn Mem 21: 597-605.

Holtzman-Assif O, Laurent V, Westbrook RF (2010). Blockade of dopamine activity in the nucleus accumbens impairs learning extinction of conditioned fear. Learn Mem 17: 71-75.

Horvitz JC (2000). Mesolimbocortical and nigrostriatal dopamine responses to salient non-reward events. Neuroscience 96: 651-656.

Inoue T, Izumi T, Maki Y, Muraki I, Koyama T (2000). Effect of the dopamine $\mathrm{D}(1 / 5)$ antagonist SCH 23390 on the acquisition of conditioned fear. Pharmacol Biochem Behav 66: 573-578.

Iordanova MD (2009). Dopaminergic modulation of appetitive and aversive predictive learning. Rev Neurosci 20: 383-404.

Iordanova MD, Westbrook RF, Killcross AS (2006). Dopamine activity in the nucleus accumbens modulates blocking in fear conditioning. Eur J Neurosci 24: 3265-3270.

Lattal KM, Maughan DK (2012). A parametric analysis of factors affecting acquisition and extinction of contextual fear in C57BL/6 and DBA/2 mice. Behav Processes 90: 49-57.

Maren S, Holmes A (2016). Stress and fear extinction. Neuropsychopharmacology 41: 58-79.

Matsumoto M, Hikosaka O (2009). Two types of dopamine neuron distinctly convey positive and negative motivational signals. Nature 459: 837-841.

Menezes J, Alves N, Borges S, Roehrs R, de Carvalho Myskiw J, Furini CR et al (2015). Facilitation of fear extinction by novelty depends on dopamine acting on D1-subtype dopamine receptors in hippocampus. Proc Natl Acad Sci USA 112: 1652-1658.

Nasser HM, McNally GP (2012). Appetitive-aversive interactions in Pavlovian fear conditioning. Behav Neurosci 126: 404-422.

National Institutes of Health (1985). NIH Publication 86-23 Revised. In Guide for the care and use of laboratory animals. Public Health Service, National Institutes of Health.

Neve K (2009). The Dopamine Receptors, 2nd edn. Humana Press: New York, NY, USA.

Nishi A, Kuroiwa M, Shuto T (2011). Mechanisms for the modulation of dopamine $\mathrm{D}(1)$ receptor signaling in striatal neurons. Front Neuroanat 5: 43.

O'Sullivan GJ, Dunleavy M, Hakansson K, Clementi M, Kinsella A, Waddington JL (2008). Dopamine D1 vs D5 receptor-dependent induction of seizures in relation to DARPP-32, ERK1/2 and GluR1-AMPA signalling. Neuropharmacology 54: 1051-1061.

Pezze MA, Feldon J (2004). Mesolimbic dopaminergic pathways in fear conditioning. Prog Neurobiol 74: 301-320.

Raczka KA, Mechias ML, Gartmann N, Reif A, Deckert J, Pessiglione $\mathrm{M}$ et al (2011). Empirical support for an involvement of the mesostriatal dopamine system in human fear extinction. Transl Psychiatry 1: e12.

Redgrave P, Prescott TJ, Gurney K (1999). Is the short-latency dopamine response too short to signal reward error? Trends Neurosci 22: 146-151.

Rey CD, Lipps J, Shansky RM (2014). Dopamine D1 receptor activation rescues extinction impairments in low-estrogen female rats and induces cortical layer-specific activation changes in prefrontalamygdala circuits. Neuropsychopharmacology 39: 1282-1289.

Rossato JI, Bevilaqua LR, Izquierdo I, Medina JH, Cammarota M. (2009). Dopamine controls persistence of long-term memory storage. Science 325: 1017-1020.

Salamone JD (1994). The involvement of nucleus accumbens dopamine in appetitive and aversive motivation. Behav Brain Res 61: 117-133. 
Schultz W, Apicella P, Ljungberg T (1993). Responses of monkey dopamine neurons to reward and conditioned stimuli during successive steps of learning a delayed response task. J Neurosci 13: 900-913.

Schultz W, Dickinson A (2000). Neuronal coding of prediction errors. Annu Rev Neurosci 23: 473-500.

Wagner A (1981). SOP: a model of automatic memory processing in animal behavior. In: Spear NE, Miller RR (eds). Information Processing in Animals: Memory Mechanisms. Erlbaum: Hillsdale, NJ, USA, pp 5-47.

Weber M, Hart J, Richardson R (2007). Effects of D-cycloserine on extinction of learned fear to an olfactory cue. Neurobiol Learn Mem 87: 476-482.
Wietzikoski EC, Boschen SL, Miyoshi E, Bortolanza M, Dos Santos LM, Frank M et al (2012). Roles of D1-like dopamine receptors in the nucleus accumbens and dorsolateral striatum in conditioned avoidance responses. Psychopharmacology (Berl) 219: $159-169$.

Wood SC, Anagnostaras SG (2009). Memory and psychostimulants: modulation of Pavlovian fear conditioning by amphetamine in C57BL/6 mice. Psychopharmacology (Berl) 202: 197-206.

Zweifel LS, Fadok JP, Argilli E, Garelick MG, Jones GL, Dickerson TM et al (2011). Activation of dopamine neurons is critical for aversive conditioning and prevention of generalized anxiety. Nat Neurosci 14: 620-626.

Supplementary Information accompanies the paper on the Neuropsychopharmacology website (http://www.nature.com/npp) 